\title{
Investigation on the Poor Computer Graphic Design Skills among Art and Design Students at University
}

\author{
Twebaze Collins Bagiritima ${ }^{1}$, John Michael Tesha ${ }^{2}$, Muturi Kimani ${ }^{{ }^{*}}$ \\ ${ }^{l}$ Department of Art and Industrial Design, Faculty of Vocational Studies, Kyambogo University, Kampala, \\ Uganda \\ ${ }^{2}$ School of Energy, Geoscience, Infrastructure and Society, Institute of Petroleum Engineering Heriot-Watt \\ University - Edinburgh, EH14 4AS, Scotland United Kingdom
}

*Corresponding Author: Muturi Kimani, Department of Art and Industrial Design, Faculty of Vocational Studies, Kyambogo University, Kampala, Uganda

\begin{abstract}
The study that was carried out involved examining the state of students offering computer graphic design in third year. The research discovered that the skills acquired by doing computer graphics in the same year of study are not equally the same thereby introducing differences in performances. The purpose of this study was to investigate the impact of computer skills on the performance of students offering Art and Design programme at one of the universities in East Africa. The research focused on finding out why most students score low in computer graphic design-a course taught at one of the Universities in Uganda.

The main findings of the study were that most students enroll in university without relevant computer skills, the performance in graphic design is affected by the lack of these skills and yet it is though that early effective training in computer skills could help bring these students to the same level of understanding the use of computer software applications in art and design or in graphic design. According to the findings, most students score between 60 and 69 percent and others between 50 and 59 percent in graphic design course unit. A few students scored 70-79 percent with none scoring 80 percent and above in the same course unit (graphic design). Therefore the general performance in graphic design is not good.
\end{abstract}

Keywords: Art education, Graphic Design, Computer Graphics, Students' Skills

\section{INTRODUCTION}

The use of computer and learning graphic designs at third year of university level is very essential to students who do graphic design, [1]. Therefore, students are must be assessed in this programme (art and design) on the use of computer graphic design programs (applications) like Adobe creative suite master collection, CorelDraw and others that can help in producing good $2 \mathrm{D}$ and $3 \mathrm{D}$ visual graphic works during and after the course of study at university.

The researcher noticed that some of the course works exhibited at the end of the semester are inadequately designed; that is to say, some graphic design works are inappropriately worked on, for example use of poorly calculated pixels and dimensions affects print quality hence dissatisfactory outcomes (printed or exhibited work). However those who sought and acquired the skill privately and had enough training exhibit good quality work (graphic designs).

Considering this imbalance in performance, the researcher hoped to identify possible ways of bridging the gap between the weak students and those who perform excellently in graphic design.

\subsection{Purpose of Study}

The purpose of this study was to investigate the poor computer skills as observed in their performance in graphic design at university.

\subsubsection{Objectives}

The researcher hoped that by the end of the study, the following would be achieved:

- Need to establish if students have any computer skills.

International Journal of Humanities Social Sciences and Education (IJHSSE)

Page | 61 
- Evaluate and judge students' performance in computer graphic design.

- Recommendation of measures to improve on the students' computer skills.

\subsubsection{Hypothesis}

Prior training in computer skills has a big impact on boosting performance of students doing computer graphics in art and design programme taught at university.

\subsection{Scope of Study}

The researcher intended to carryout studies with limits indicated as follows:

- This research was to be carried out at one of the universities located in East Africa.

- This was because the University is one of public institutions in which implementation of government policies and research in education should be executed to fulfill the national goals of education. This would particularly address the impact of computer knowledge among the students offering graphic design as an elective in Art and Design programme.

- This study was to focus on establishing information about students' knowledge about computer applications in order to discover more about the study.

- During this study, the researcher was looking at the performance of Art and Design students in computer graphics in relation to their skills in computer. Therefore data was gathered from students, lecturers, and other available sources in the university.

\subsection{Significance of the Study}

The researcher hoped that;

- This research would help the Art and Design departments in universities to identify the major weaknesses in students caused by lack of computer knowledge in general which would enable stake holders to revise the curriculum in order to facilitate early training in computer knowledge and skills.

- The lecturers handling graphic design would be facilitated to use the suggested means to equip the students with the required skills early enough and these Students would be able to excel in performance as far as computer graphics is concerned.

- It was also expected that stake holders in the ministries of education in government were to be enlightened on what students need to be well skilled before enrolling at university. This would help pupils to get computer training at an early age (elementary and high school) in order to eliminate computer illiteracy.

- Other researchers should base on this study in order to build on these findings to come up with more ideas in the same line of studying.

The literature presented below exposes the impact of computer skills on the performance of students in the area of graphic design.

According to Bertoline and Laxer (2002), he states that; Computer graphics can and will have a profound effect on every type of business, industry, government, education, and the home. But it will take a very special type of education to prepare this next generation of computer graphics specialists [2]. The author above explains that computer graphics will have a very significant impact on every aspect of life and every field of study and therefore it is important to provide special education to prepare learners for the generation of computer literates. In twenty years to come most jobs globally will require computer skills and most equipment used in our daily life will require scientific understanding which leaves us with a big question in mind, "where will the World be in this computer technology era?".

In most sub-Sahara African schools, computer technology application in schools has become part of the teaching and learning improvement tools. Both the students and teachers equally need to acquire computer knowledge and skills to increase their chances of getting a job or retaining one [3]

According to a survey done by Evans, Romeo, Bahrehmand, Agenjo, \& Blat, 3D Digital content created on Web has shown that there is great need for 3D graphics both from academic and commercial arenas. It is explained that several tools and interfaces have brought the $3 \mathrm{D}$ content and scene creation in the web context [4]. 


\subsection{Computer Skills amongst Students Is Necessary}

Graphics is an important tool for students doing art and design, therefore should be well catered for during studies [5]. The use of computer exists almost at every stage in modern life which makes it hard for people without computer skills to advance in professional and personal life [6].

According to T. Jita (2016), Pre-service teachers reports on competences for teaching science through information and communication technologies during teaching practice, in, University of the Free State, 2016. The researcher says that, the use of ICTs in education, while being highly desirable from a number of standpoints, has never been an essential component in school.

The some schools which learners go through do not teach and examine computer which contributes to the missing of skills needed for higher education. The national curriculum and the examine bodies have not emphasized the teaching and assessing learners in computer skills.

Lack of focused mind and determination to learn lead to students being taken up by other sites especially where computers are connected to internet. This leads to failure to concentrate on programs that may be helpful in their studies and daily life application. Students need guidance on how to learn programs and search for necessary information that can contribute to their academic excellence as well as improving their skills [7].

B. Eisenberg and D. Johnson (2002) asks; "Can the student who operates a computer, well enough to play a game, send e-mail or surf the Web be considered computer literate? Will a student who uses computers in school only for running tutorials or an integrated learning system have the skills necessary to survive in our society? Will the ability to do basic word processing be sufficient for students entering the workplace or post-secondary education?"

The above explains that most learners acquire computer skills and knowledge which may not necessarily help them to solve life problems for example, at work place or higher education.

Therefore they may need to have more packages for specialized training; in this case graphic design application packages are a good venture for students who do art and design [8].

\subsection{Students' Performance Gap in Computer Studies}

Male students had slightly better performance in compulsory computer studies. In addition to that, the core hardware or lab-based software courses reportedly were not selected by the female students at university $[9,10]$. There is already a gender gap in acquiring skills despite the fact that this research is not about gender differences.

One researcher carried out a study and results showed students who thought had mastered word processing actually knew very little about spreadsheet and database applications. In addition to that, they had not got any exposure in ethical, social, legal and global issues [11]. Meaning that even for graphic design, nothing totally was covered since the researcher did not capture it in the research.

\subsection{Need for Computer Training or Teaching}

R. Hawkins and A.E. Paris(1997) say that European American students, African American and Hispanic students come to the university with a significantly thinner computer skills. However, our concern is that the universities have little recognition of these deficiencies. Consequently, the disparity in computer skills increases and follows from their freshman to senior year of study [12]. The above authors explain that however much one is used to utilization of computerized services, this cannot guarantee skill acquisition in an individual because it requires a lot of training.

When a student or teacher has got enough computer skills, they stand high chances of excelling at work especially when the work needs computer applications. A study carried out showed that when one uses computerized graphic design program immensely during their learning, there is a large and positive influence on the level of practical media skills application [13].

\subsection{Suggestions on Computer Skills}

Universities must do more than simply make computers available to their students. Several universities are already being recognized for their responses to this problem, and we believe these programs can serve as models for those that are doing less well in this regard. In the end, the problem we have described is thus far one that requires deliberate programme development to eliminate the real differences in computer skills that students bring to the university [12]. 
The students should understand the important Graphic design programs and how they operate. Students should be inspired to do more practice like the way they do in other areas of study, the computer laboratories should be utilized to the maximum through regular opening and having experts available to help students understand tools used in different computer programs relevant to the studies to be covered.

\section{Methodology}

This part introduces the method and procedures used in the collection of data. The research design, sampling procedures, sample, and research instruments were discussed under this chapter.

\subsection{Research Design}

The researcher went through the following processes while carrying out studies;

- Selection of title

- Defining and explaining the title

- Collecting information from the library, internet, magazines, journals and resource persons.

- Review of the related literature

- Choosing a target population and sample

- Deciding on the method of data collection

- Preparing and distribution instruments for data collection

- Collecting and organizing data for analysis

- Analyzing data

- Reporting.

\subsection{Population}

The population of the study included lecturers of graphics as key informants and students in final year at University in graphic design class as main respondents. This was because the students and lecturers were involved in computer graphics.

\subsection{Sample}

This research considered a total number of seventeen respondents. Three were lecturers at the department of art and design, in the sampled university. The fifteen were students offering graphic design in final year.

\subsection{Instruments}

The researcher got primary information directly from respondents using formulated Questionnaires under the guidance of the supervisor in order to facilitate statistical and descriptive data analysis.

The questionnaires were distributed to students who did computer graphics and were guided by the researcher to answer the questions appropriately. Secondary data will be obtained from text books, newspapers, internet, resource persons and journals in order to enhance on the findings in primary data. A few oral questions in form of interview were asked to students in order to supplement the collected data.

\subsection{Procedure}

The researcher will present questionnaires to the supervisor for approval and discussion in order to evaluate the quality of data to be collected from the respondents.

Face to face interviews were made between the lecturer and student respondents.

Appointments and permission from individual lecturers and students were sought in order to access information.

The designed questionnaires were given to the sampled subjects in order to collect data.

There was use of questionnaires to guide the respondents to provide necessary data. Brief introduction 
of topic was done in order to ensure quality data. The collection of data was followed by compiling through use of data analysis methods like tallying and other statistical procedures. For purposes of relevancy and validity, questions in the questionnaire addressed the research objectives and tested the hypothesis.

\subsection{Data Analysis}

Data obtained was analyzed by comparing the both the hypothesis and the results reflected on the respondents' answers.

The data was statistically and qualitatively analyzed in order to test the hypothesis and final reporting of research findings was done to come up with a report book.

\section{RESULTS AND DISCUSSION}

This chapter presented the findings of the study based on the objectives of the research study. It discussed the findings in line with the objectives of the study. The study was presented statistically in tabulation form, using illustrations like graphs, and using explanatory notes.

\subsection{Bio Data of Respondents Based on Region, Age and Sex}

The total number of respondents was 17 with 14 students and 3 lecturers of whom 11 were males and 6 were females. Most students in the graphic design class studied from central and western region for their advanced level education as indicated in Table

Table1: Age bracket of respondents

\begin{tabular}{|l|l|l|}
\hline \multicolumn{1}{|c|}{ Age group/years } & \multicolumn{1}{c|}{ frequency } & \multicolumn{1}{c|}{ Percentage\% } \\
\hline $20-25$ & $13 \quad$ & 76.4 \\
\hline $25-30$ & 2 & 11.8 \\
\hline $30-35$ & 1 & 5.9 \\
\hline 35 and above & 1 & 5.9 \\
\hline Total & $\mathbf{1 7}$ & $\mathbf{1 0 0}$ \\
\hline
\end{tabular}

Basing on the information on Table above the highest number of respondents was 20-25 taking $76.4 \%$ of the whole population of respondents, followed by those between 25-30 years with the $11.8 \%$. These age groups were found having the highest number of people because they are the majority in the graphics class since most of the them were admitted on A' level entry to university.

\subsection{Acquisition of Computer Skills by Students}

Most students used computers for their first time in the period between 2000 and 2005 that's to say; 3 females and 4 males in the period between 1995 and 2000 registered the least and 2005-2010 registered respectively the least number of females as indicated in Figure

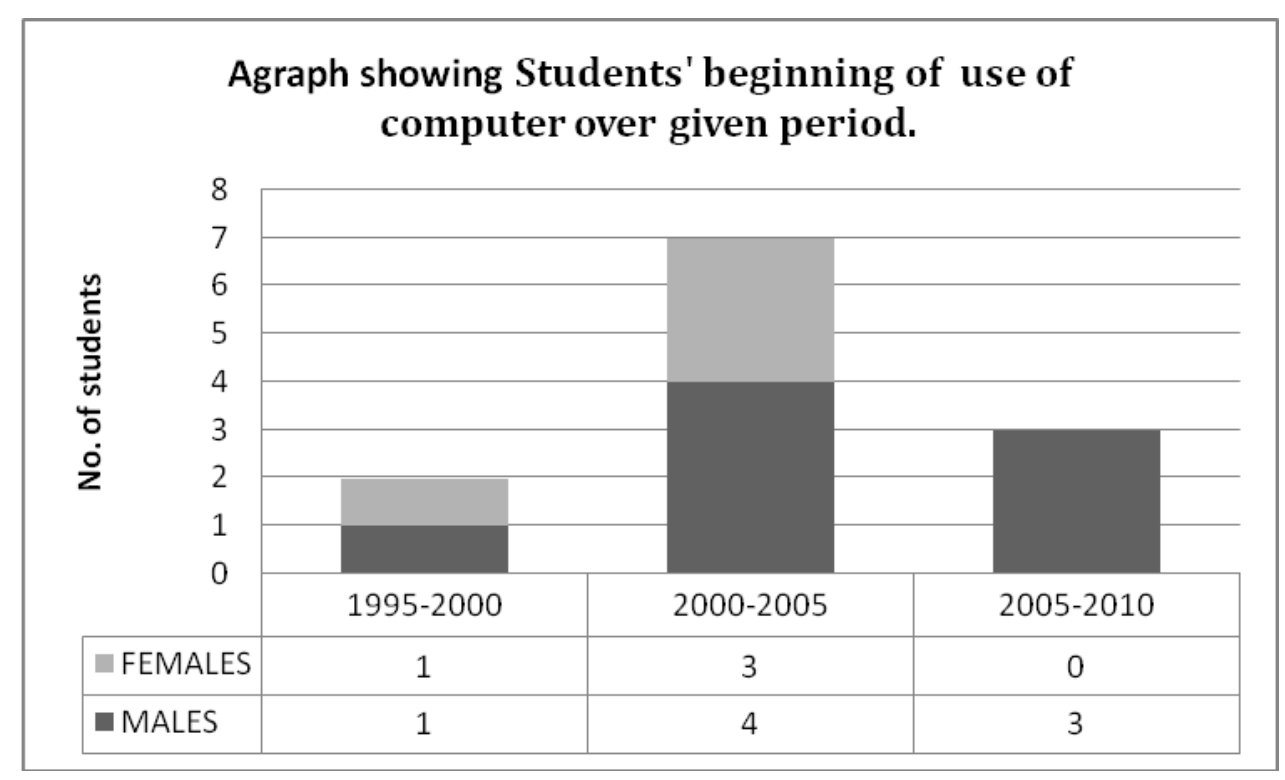

Figure1: Acquisition of computer skills by students in early period 
The computer programs used at the first encounter with computers include; Microsoft word processing package[14], media player, and paint of which 1 respondent out of 14 used paint which is related to art and design. However, students were able to mention programs like CorelDraw, Adobe suite collection which are used in graphic design of which some were familiar with; though most of them had not acquired enough skills.

It was observed in Figure that $42 \%$ of the student respondents use computer at least twice a week, $25 \%$ everyday, $17 \%$ once a week and the rest $16 \%$ which shows that very few students use computer every day. It was reported by the three lecturers that; three quarters of the students doing Bachelor's degree in art and design students are not well conversant with computer design graphics applications. It was noted that students are not equally active in terms of hands on performance in computer graphics and most students join university with no computer skills.

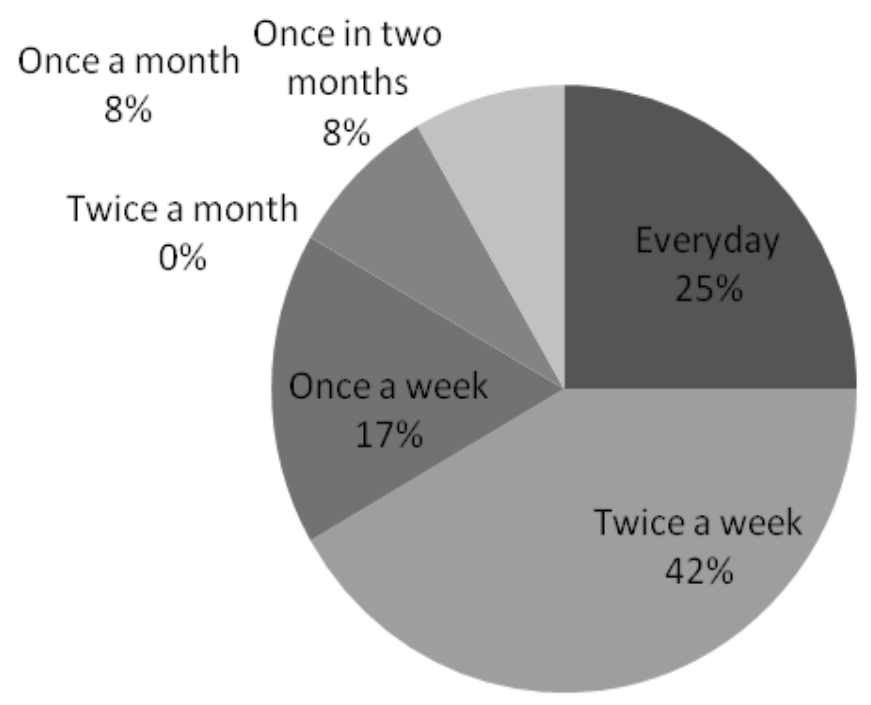

Figure2: Pie chart showing frequency of computer usage in particular intervals of time.

Therefore; there are very few students who had learnt the use of computer in graphic designs from early years of education or beginning of the course and the only the basics had been acquired by most students in final year at university.

\subsection{Evaluation and Judgment of Students' Performance in Computer Graphics}

Most students doing Bachelor of art and design in final year started learning computer in their second year of study; a time when the skills were required in execution of graphic design. The numbers of students owning computers out of 14 respondents are 6 and 8 don't own any computer, it is 33 by $67 \%$ as indicated in Figure.

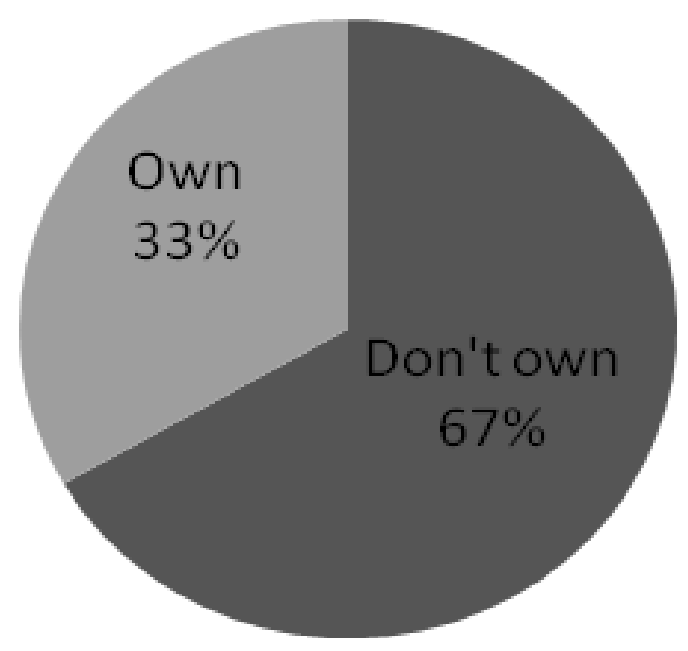

Figure3: Pie chart showing computer ownership. 
Majority of students did not own computers; it was noted that most students access computers by borrowing from friends and others from the department's small computer laboratory. The assistance in terms of guidance was provided by lecturers mostly, laboratory assistant and friends. However some of them had learnt through self-discoveries by use of program tutorials and books from the library for example Adobe Photoshop tutorial manual guide.

The graph and pie chart in Figure show ways how students obtain assistance in order to get skills in computer. The lecturers contribute 50\% students' acquisition of computer skills, followed by friends; $29 \%$, self-discovery $14 \%$, books and tutorials $7 \%$.
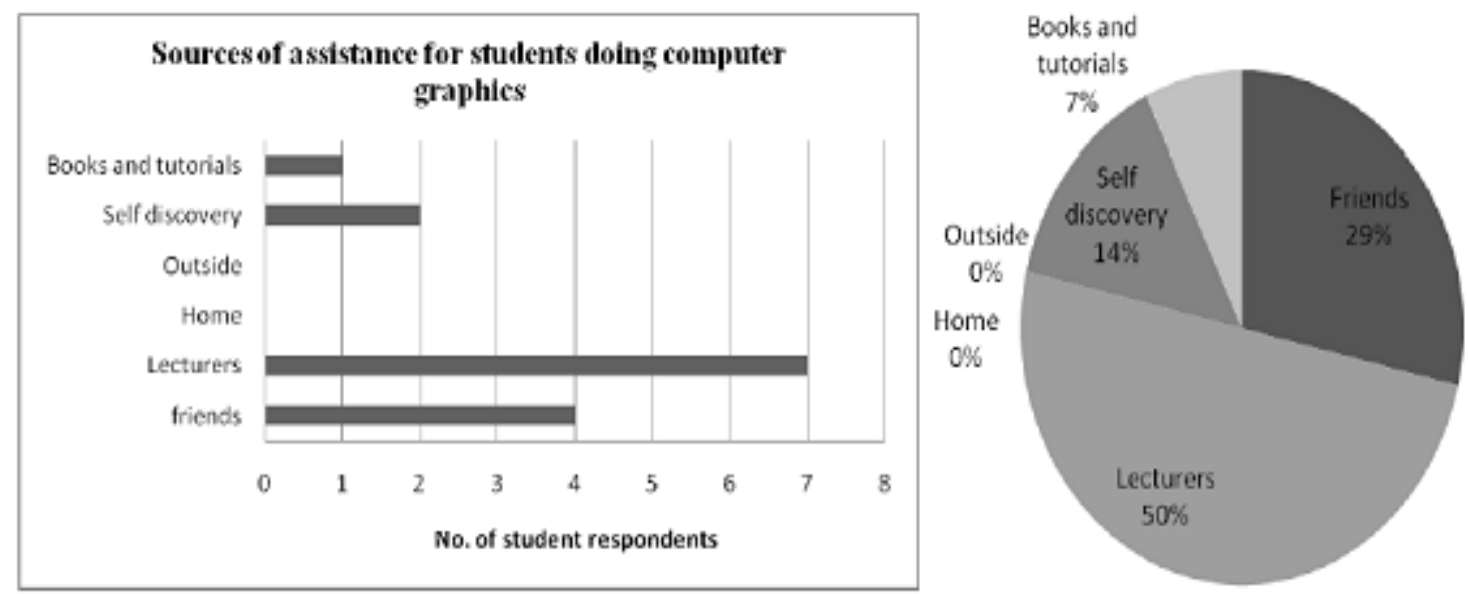

Figure4: Pie chart showing sources assistance for acquisition of computer skills

The Table shows the general trend of performance in graphic design from first year to third year.

Table2: General trend on performance of respondents in computer Design class.

\begin{tabular}{|l|l|}
\hline \multicolumn{1}{|c|}{ General Performance Trend } & Number of respondents out of 14 Students \\
\hline Rising & 7 \\
\hline Lowering & 5 \\
\hline Constantly high & 1 \\
\hline Constantly low & 1 \\
\hline
\end{tabular}

From the information given in the Figure, the performance of students mainly characterized by majority having a rising trend of $50 \%$, lowering trend of $36 \%$, constantly low of $8 \%$ and constantly high of $8 \%$. This showed that most students were still trying to improve on their performance which had not reached the expected level.

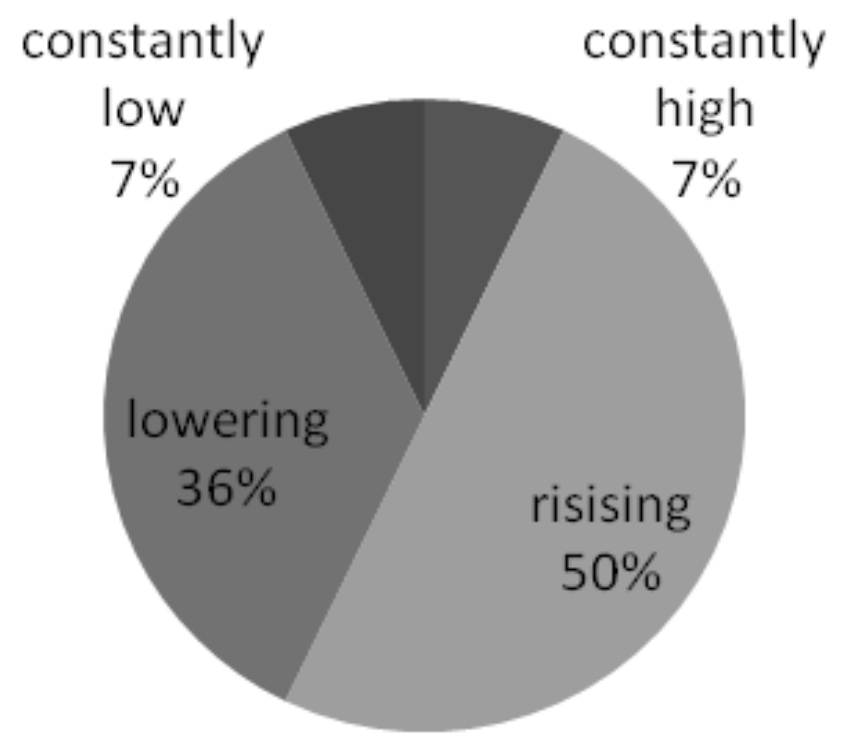

Figure5: Pie chart showing student general performance in graphic design 
It was observed in Figure, 54\% of respondents scored between $60-69 \%$, followed by $33 \%$ with 70 $79 \%, 13 \%$ with $50-59 \%$, with no one above $80 \%$ and below $50 \%$.

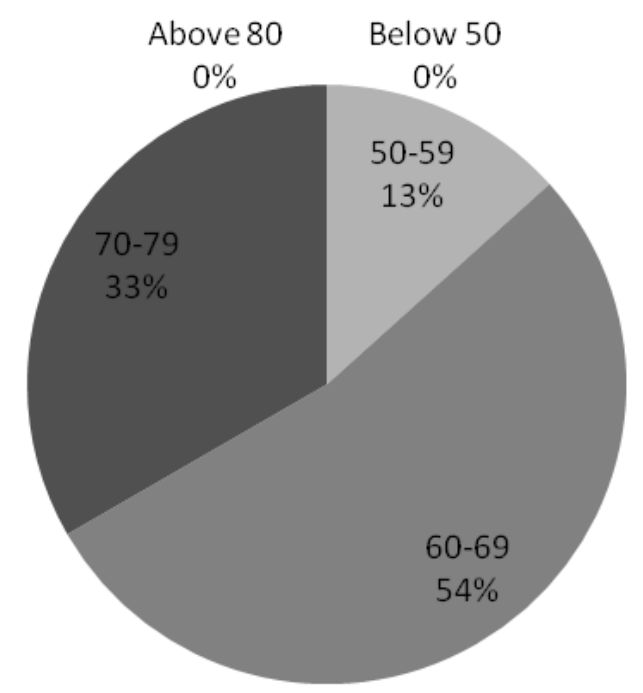

Figure6: Pie chart showing scores in percentages(\%)

This shows that most students scored between $60-69 \%$ which registered the highest; this reflects the fair performance which indicates that more efforts are needed to improve on the performance. However, the lecturers said that the performance is generally good graphic design from first year to third year even though computer design affects the performance. They also added that most students in third year get between $60-70 \%$ mark scores.

\subsection{Measures to Improve Students' Computer Skills}

All respondents strongly agreed that there are challenges in computer graphics highlighting a few including:

- A student not having their own computer set which limited them from self-study and discoveries.

- Lack of instructors which tempts most students to rely on their friends' guidance.

- Programs being hard to learn.

- Most of the skills not professionally taught at the art and industrial design department.

- Students not having previous experience in computer skills.

- Forgetting due non ownership due to less practice.

- Limited guidance from lecturers and laboratory assistant.

- Gender stereotyping that; females are reluctant to learning computer skills.

The major cause of poor performance which was identified and ranked first was that students had late training in computer graphics, followed by lack of guidance to students.

The former was seconded by 12 respondents out of 14 and then other reasons like:

- Complication in understanding concepts of computer programs.

- Students' reluctance to learn.

- Gender disparities.

- Poor time tabling by the department of art and design by giving less time for training hands on.

It was noted that 6 out of 14 student respondents have utilized the departments computer laboratory though the computers available are very few compared to the class. The other 8 said that they have always dependence on visiting friends and borrowing. The students were able to give their suggestions in order to improve their performance as well as facilitate their acquisition of computer skills and these included: 
- Providing more computer sets to increase on the student-computer ratio.

- Recruit more instructors with professional knowledge of computer graphic design.

- Employ more appropriate methods of teaching for example; learner centered teaching to reduce on gender stereotyping and students reluctance to be active.

- Extension of computer laboratory to increase on the capacity of both students and the computer sets.

- Provision of special training to students who are less privileged for example the poor and females since gender is also an issue.

Individual projects took the first place with $57 \%$, both methods take $29 \%$ and then group projects $14 \%$ as means the university uses to train students in computer graphic design.

Student respondents as indicated in Figure said they benefited from individual projects because they help individuals to test themselves and discover their potential in doing computer graphics.

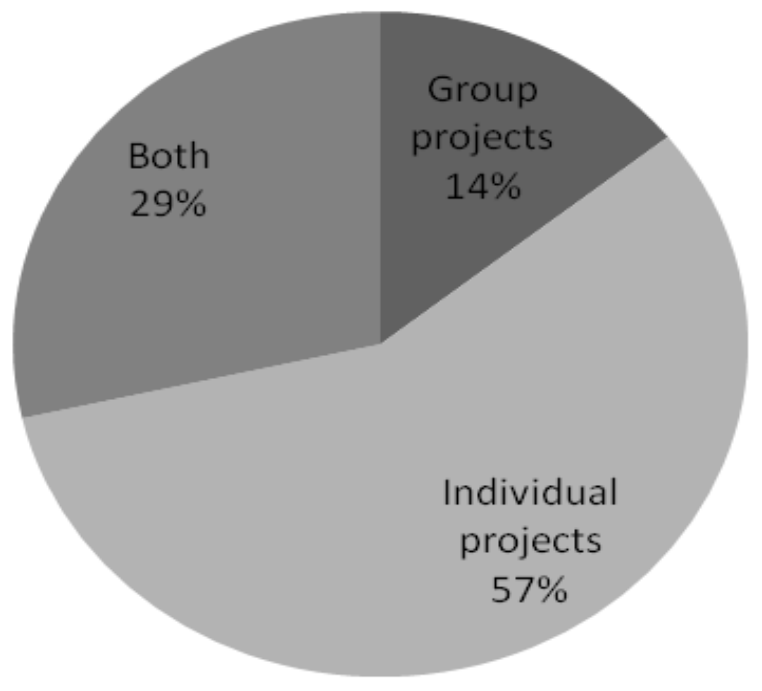

Figure7: Methods of executing work in computer graphics done by respondents.

A student interviewed said; "I taught myself; I did not know anything about computer" which implies that some students put effort to attain skills by themselves which proves inadequate effort [15] for universities and schools to train students in computer graphics.

However group projects enabled some students to acquire skills by learning from their group mates who knew computer more than they did.

Lecturers strongly accepted that there are challenges experienced while guiding students in computer graphics and these include:

- Inadequate computers for individual student practice.

- Period allocated to computer studies and graphic design applications are not enough.

- Absenteeism of students leads to missing of computer training sessions.

- The university and students lack funds to facilitate graphic design lesson requirements like large format printing, scanners and other necessary materials.

- However, one of the lecturers informed the researcher that the university has tried to facilitate training computer skills by providing computer sets and also employed experts in information technology to further deliver professional knowledge and skill.

The lecturers (respondents) recommended that computer lessons for art and design programme should be introduced right from the beginning of the course.

Still on the same note the computer laboratory should be equipped with enough high quality computer machines and devices required for computer training 
A bigger place for computer training should be secured to cater for the big number of students studying computer graphics as it seen in Figure.

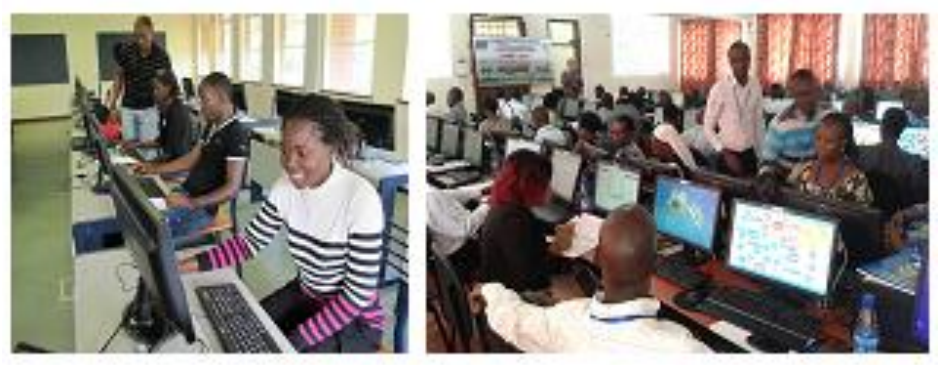

Figure8: One of the Ugandan University's computing centers

\section{CONClusion}

It was discovered that most students join university without relevant computer skills that can help in execution of tasks in computer graphic design which results into relatively low performance. The university has no special training for art and design students in computer skills and students therefore have to learn on their own. The little training acquired comes at the time of executing tasks given to students in second year and third year.

Most students score between 60 and 69 percent and others between 50 and 59 percent. Basing on the research conducted presentation, analysis and interpretation of findings drawn; it's evident that students' scores were low hence lack relevant computer skills right from the beginning of study at university which will continue to affect the students' performance not only in art and design study programme but also in other areas of study where computer skills are required. This presents the recommendations to stake holders in universities, government and the ministry of education. The institution should put efforts to expand the information technology sector in order to improve on access of computer and provision of necessary skills for students. This will be achieved by installing more computers and employment of experts to provide professional knowledge and training. The institution should also provide adequate training to make student achieve appreciable level of performance in computer applications.

The Government should intervene and sensitize the public about the importance of computer skills. Provide schools with enough computers and build more laboratories to improve on the skills of learners before they join higher institutions.

Ministry of education under the government in liaison with different bodies of the ministry, should secure more funds for information technology development in education institutions. Computer lessons should be compulsory at lower levels of education (Elementary, middle and high schools) to inculcate a strong background of computer literacy among learners.

\section{AREA OF FURTHER RESEARCH}

It is deemed necessary that research should be carried out on the following; the impact of individual projects on students' performance in computer graphics, the significance of friends in execution of work in computer graphics, Bachelor's degree in art and design study programme may need more than 3 years in order to help students acquire all the necessary skills in computer graphics because time is not enough for students to have enough training.

\section{REFERENCES}

[1] I. Jackson, Gestalt- A Learning Theory for Graphic Design Education, International Journal of Art \& Design Education, 27 (2008) 63-69.

[2] G.R. Bertoline, C. Laxer, A knowledge base for the computer graphics discipline, in: International Conference on Computer Graphics and Interactive Techniques: ACM SIGGRAPH 2002 conference abstracts and applications, 2002, pp. 15-15.

[3] C.B. Mindebele, Z.F. Hlophe, Computer literacy among practical arts teachers in Swaziland vocational schools, Journal of Vocational Education and Training, 53 (2001) 341-352.

[4] A. Evans, M. Romeo, A. Bahrehmand, J. Agenjo, J. Blat, 3D graphics on the web: A survey, Computers \& Graphics, 41 (2014) 43-61. 
[5] J.F. Hughes, A. Van Dam, J.D. Foley, M. McGuire, S.K. Feiner, D.F. Sklar, K. Akeley, Computer graphics: principles and practice, Pearson Education, 2014.

[6] M. Milic, I. Škoric, The impact of formal education on computer literacy, International Journal of Emerging Technologies in Learning (iJET), 5 (2010).

[7] T. Jita, Pre-service teachers' competences for teaching science through information and communication technologies during teaching practice, in, University of the Free State, 2016.

[8] M.B. Eisenberg, D. Johnson, Learning and Teaching Information Technology--Computer Skills in Context. ERIC Digest, (2002).

[9] M. Kordaki, I. Berdousis, Course Selection in Computer Science: Gender Differences, Procedia-Social and Behavioral Sciences, 116 (2014) 4770-4774.

[10] J. Ehrlinger, E.A. Plant, M.K. Hartwig, J.J. Vossen, C.J. Columb, L.E. Brewer, Do Gender Differences in Perceived Prototypical Computer Scientists and Engineers Contribute to Gender Gaps in Computer Science and Engineering?, Sex roles, 78 (2018) 40-51.

[11] N. Hindi, D. Miller, J. Wagner, Computer literacy: Implications for teaching a college-level course, Journal of Information Systems Education, 13 (2002) 143-152.

[12] R. Hawkins, A.E. Paris, Computer literacy and computer use among college students: Differences in black and white, Journal of Negro Education, (1997) 147-158.

[13] H.S. Zaghloul, M.D. Rabeh, The Impact of a Computer Graphics Program for Acquisition of Some Practical Media Skills for Mass Communicators in Media Schools, International Journal of Educational Sciences, 14 (2016) 187-194.

[14] L.A. Sump, B.C. Mottau, L.A. LeBlanc, Evaluating Behavioral Skills Training to Teach Basic Computer Skills to a Young Adult with Autism, Behavior Analysis in Practice, 12 (2019) 331-334.

[15] D. Alique, M. Linares, The importance of rapid and meaningful feedback on computer-aided graphic expression learning, Education for Chemical Engineers, (2019).

\section{AUTHORS' BIOGRAPHY}

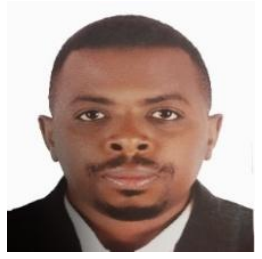

Twebaze Collins Bagiritima is the main author of this manuscript and pursued his studies in Vocational studies in Art and Design with Education from Kyambogo University, Kampala, Uganda

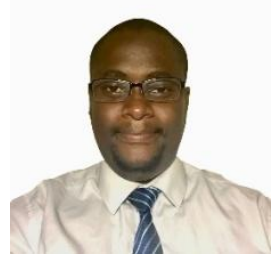

John Michael Tesha is currently at the Institute of Petroleum Engineering from Heriot-Watt University - Edinburgh, EH14 4AS, Scotland, United Kingdom

He recently published in the International Journal of Petroleum and petrochemical engineering (ARC Journals)

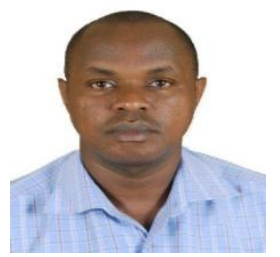

Muturi Kimani is currently a Senior Lecturer at Kyambogo University, Kampala, Uganda

Director/Founder of TEXFAD Vocational Business incubator-Uganda

Citation: Twebaze Collins Bagiritima, Muturi Kimani, et.al. "Investigation on the Poor Computer Graphic Design Skills among Art and Design Students at University". International Journal of Humanities Social Sciences and Education (IJHSSE), vol. 6, no.10, 2019, pp. 61-71. doi: http://dx.doi.org/10.20431/2349-0381. 0610007.

Copyright: (c) 2019 Authors. This is an open-access article distributed under the terms of the Creative Commons Attribution License, which permits unrestricted use, distribution, and reproduction in any medium, provided the original author and source are credited. 